Article

\title{
Application of Sentinel 2 MSI Images to Retrieve Suspended Particulate Matter Concentrations in Poyang Lake
}

\author{
Huizeng Liu ${ }^{1,2}$ (D), Qingquan $\mathrm{Li}^{2}$, Tiezhu Shi ${ }^{2,3}$, Shuibo $\mathrm{Hu}^{2,3}$, Guofeng Wu 2,3,* \\ and Qiming Zhou ${ }^{1, *}$ (D) \\ 1 Department of Geography, Hong Kong Baptist University, Hong Kong, China; huizengliu@life.hkbu.edu.hk \\ 2 Key Laboratory for Geo-Environmental Monitoring of Coastal Zone of the National Administration of \\ Surveying, Mapping and GeoInformation \& Shenzhen Key Laboratory of Spatial Smart Sensing and \\ Services, Shenzhen University, Shenzhen 518060, China; liqq@szu.edu.cn (Q.L.); tiezhushi@szu.edu.cn (T.S.); \\ hsb514@163.com (S.H.) \\ 3 College of Life Sciences and Oceanography, Shenzhen University, Shenzhen 518060, China \\ * Correspondence: guofeng.wu@szu.edu.cn (G.W.); qiming@hkbu.edu.hk (Q.Z.)
}

Received: 27 May 2017; Accepted: 19 July 2017; Published: 23 July 2017

\begin{abstract}
Suspended particulate matter (SPM) is one of the dominant water constituents in inland and coastal waters, and SPM concnetration $\left(C_{\mathrm{SPM}}\right)$ is a key parameter describing water quality. This study, using in-situ spectral and $C_{\mathrm{SPM}}$ measurements as well as Sentinel 2 Multispectral Imager (MSI) images, aimed to develop $C_{\mathrm{SPM}}$ retrieval models and further to estimate the $C_{\mathrm{SPM}}$ values of Poyang Lake, China. Sixty-eight in-situ hyperspectral measurements and relative spectral response function were applied to simulate Sentinel 2 MIS spectra. Thirty-four samples were used to calibrate and the left samples were used to validate $C_{\text {SPM }}$ retrieval models, respectively. The developed models were then applied to two Sentinel 2 MSI images captured in wet and dry seasons, and the derived $C_{\text {SPM }}$ values were compared with those derived from MODIS B1 $(\lambda=645 \mathrm{~nm})$. Results showed that the Sentinel 2 MSI B4-B8b models achieved acceptable to high fitting accuracies, which explained $81-93 \%$ of the variation of $C_{\mathrm{SPM}}$. The validation results also showed the reliability of these six models, and the estimated $C_{\mathrm{SPM}}$ explained $77-93 \%$ of the variation of measured $C_{\mathrm{SPM}}$ with the mean absolute percentage error (MAPE) ranging from $36.87 \%$ to $21.54 \%$. Among those, a model based on B7 $(\lambda=783 \mathrm{~nm})$ appeared to be the most accurate one. The Sentinel 2 MSI-derived $C_{\mathrm{SPM}}$ values were generally consistent in spatial distribution and magnitude with those derived from MODIS. The $C_{\mathrm{SPM}}$ derived from Sentinel 2 MSI B7 showed the highest consistency with MODIS on 15 August 2016, while the Sentinel 2 MSI B4 $(\lambda=665 \mathrm{~nm})$ produced the highest consistency with MODIS on 2 April 2017. Overall, this study demonstrated the applicability of Sentinel 2 MSI for $C_{\text {SPM }}$ retrieval in Poyang Lake, and the Sentinel 2 MSI B4 and B7 are recommended for low and high loadings of SPM, respectively.
\end{abstract}

Keywords: suspended particulate matter (SPM); water quality; sentinel 2 MSI; Poyang Lake; remote sensing

\section{Introduction}

In water color remote sensing, case-II waters are defined as waters whose optical properties are significantly influenced by suspended particulate matter (SPM), phytoplankton, and colored dissolved organic matter (CDOM), and SPM and CDOM concentrations do not covary with phytoplankton [1]. Most of inland and coastal waters belong to case-II waters. These waters provide various benefits to society through commerce, aesthetics, tourism, recreation, and biodiversity conservation, which are 
greatly affected by water quality [2-5]. SPM is one of the main constituents and optically active matters in sediment-laden case-II waters. Moreover, SPM concentration $\left(C_{\mathrm{SPM}}\right)$ is a key parameter describing water quality because of the impacts of SPM on the light transmission, accumulation, and transportation of nutrients and contaminants in water bodies, and further on an aquatic ecosystem [6-8].

Both natural forces and anthropogenic activities may influence the distribution pattern of SPM, making the $C_{\mathrm{SPM}}$ values temporally dynamic and spatially heterogeneous [9-11]. Therefore, obtaining the information of $C_{\mathrm{SPM}}$ at high spatiotemporal resolution is necessary for understanding water quality dynamics and identifying their driving forces, and further for managing and protecting aquatic ecosystems [12]. In-situ sampling and laboratory analysis can provide accurate measurements; however, field-based analyses are costly and labor-intensive, and may fail to capture detailed spatial variation. On the contrary, satellite remote sensing can provide synoptic observations from visible to near infrared (NIR) spectral regions, which can be used to derive the $C_{\text {SPM }}$ values in water.

The spatial, temporal, spectral, and radiometric resolutions of a sensor system determine its capability in water color remote sensing [5]. Ocean color sensors, such as Coastal Zone Color Scanner (CZCS), Sea-viewing Wide Field-of-View Sensor (SeaWiFS), Moderate-Resolution Imaging Spectroradiometer (MODIS), and Geostationary Ocean Color Imager (GOCI), have advantages in more frequent revisits, higher signal-to-noise ratio (SNR), and higher radiometric sensitivity. However, those sensors hold lower spatial resolutions ranging from several hundred meters to over $1 \mathrm{~km}$, which are often challenged to monitor fine spatial structure of water parameters in inland and coastal case-II waters [13]. Therefore, land-intended satellites, such as Landsat series sensors, SPOT and GF-1 [3,14,15], have been applied to retrieve $C_{\text {SPM }}$ values of case-II waters $[5,11,12,16-18]$.

Sentinel 2 Multispectral Imager (MSI), a constellation of two satellites in sun-synchronous polar orbit, targets land and coastal zone monitoring by providing high spatial (10-60 $\mathrm{m}$ ) and temporal (2-5 days) resolution images [19]. Following the launches and completions of in-orbit commissioning phase of Sentinel 2A and Sentinel 2B, they turned operational on 28 November 2015 and 7 July 2017, respectively. MSI has 13 bands from visible to shortwave infrared (SWIR) spectral regions, providing appropriate data source to document $C_{\mathrm{SPM}}$ variations in coastal and inland waters [20].

Some studies have been carried out in retrieving water parameters using Sentinel 2 MSI data. Gernez et al. [15] applied a simulated Sentinel 2 MSI dataset to retrieve $C_{\text {SPM }}$ values in turbid estuary waters. Manzo et al. [21] investigated the sensitivity of Sentinel 2 MSI to optically active matters in Italian lakes with the simulated reflectance from bio-optical model. Dörnhöfer et al. [22] applied Sentinel 2 MSI to assess water constituents and bottom characteristics over oligotrophic lake waters. Kutser et al. [23] demonstrated the advantage of Sentinel 2 MSI over Landsat 8 OLI in retrieving suspended matters in black lakes. Toming et al. [24] obtained high fitting accuracy between in-situ data and remote-sensed reflectance from Sentinel 2 MSI for chlorophyll-a $\left(R^{2}=0.83\right)$ and dissolved organic carbon $\left(R^{2}=0.92\right)$. Moreover, the potentials of Sentinel 2 MSI on water quality monitoring in both inland and coastal waters have been anticipated [5,17,25-28].

Poyang Lake is the largest freshwater lake in China, which provides important habitats for Siberian cranes [29] and the Yangtze Finless Porpoise [30]. As a floodpath lake, SPM in Poyang Lake supplements sediment losses due to sand dredging and scouring. However, high $C_{\mathrm{SPM}}$ may deteriorate the water quality and silt channels. Therefore, some studies have been focused on deriving $C_{\mathrm{SPM}}$ in this lake. The $C_{\text {SPM }}$ monitoring in Poyang Lake has been largely dependent on the images from Landsat and MODIS Terra and Aqua sensors [9,11,12,31-34]. Recently, Li et al. [14] investigated the capability of GF 1 WFV in $C_{\mathrm{SPM}}$ estimations; however, the atmospheric correction over turbid waters is hindered by lacking SWIR bands, limiting its applications on water quality monitoring. Red and NIR bands have been frequently used to retrieve $C_{\text {SPM }}$ due to their sensitivity to $C_{S P M}[3,12,35]$. Sentinel 2 MSI has seven bands in red to NIR spectral regions, which may provide additional potential in $C_{\text {SPM }}$ retrieval. Considering the advantages in spatial, temporal, and spectral resolutions of Sentinel 2 MSI, developing Sentinel 2 MSI-based retrieval models should facilitate the $C_{\text {SPM }}$ recording in Poyang Lake. This study aimed to: (i) develop Sentinel 2 MSI-based $C_{\text {SPM }}$ retrieval models, (ii) compare Sentinel 2 MSI with 
MODIS in $C_{\mathrm{SPM}}$ estimations to validate the developed models, and (iii) to identify appropriate spectral bands for $C_{\text {SPM }}$ retrieval in Poyang Lake.

\section{Materials and Methods}

\subsection{Study Area}

Poyang Lake $\left(115^{\circ} 47^{\prime}-116^{\circ} 45^{\prime} \mathrm{E}, 28^{\circ} 22^{\prime}-29^{\circ} 45^{\prime} \mathrm{N}\right)$ is located on the southern bank of the middle Yangtze River (Figure 1). It is a floodpath lake with large fluctuations of seasonal water level variation. Its area ranges from $<1000 \mathrm{~km}^{2}$ in dry season to about $4000 \mathrm{~km}^{2}$ in wet season. The lake receives water from tributaries of five rivers (Raohe, Xinjiang, Fuhe, Ganjiang, and Xiushui), and drains into the Yangtze River through the lake mouth in the north. Suspended sediment is one of the dominant factors affecting the water quality of Poyang Lake, and its concentration fluctuates largely due to discharges from the five rivers, sand dredging activities, and backflows from Yangtze River [11,36,37].
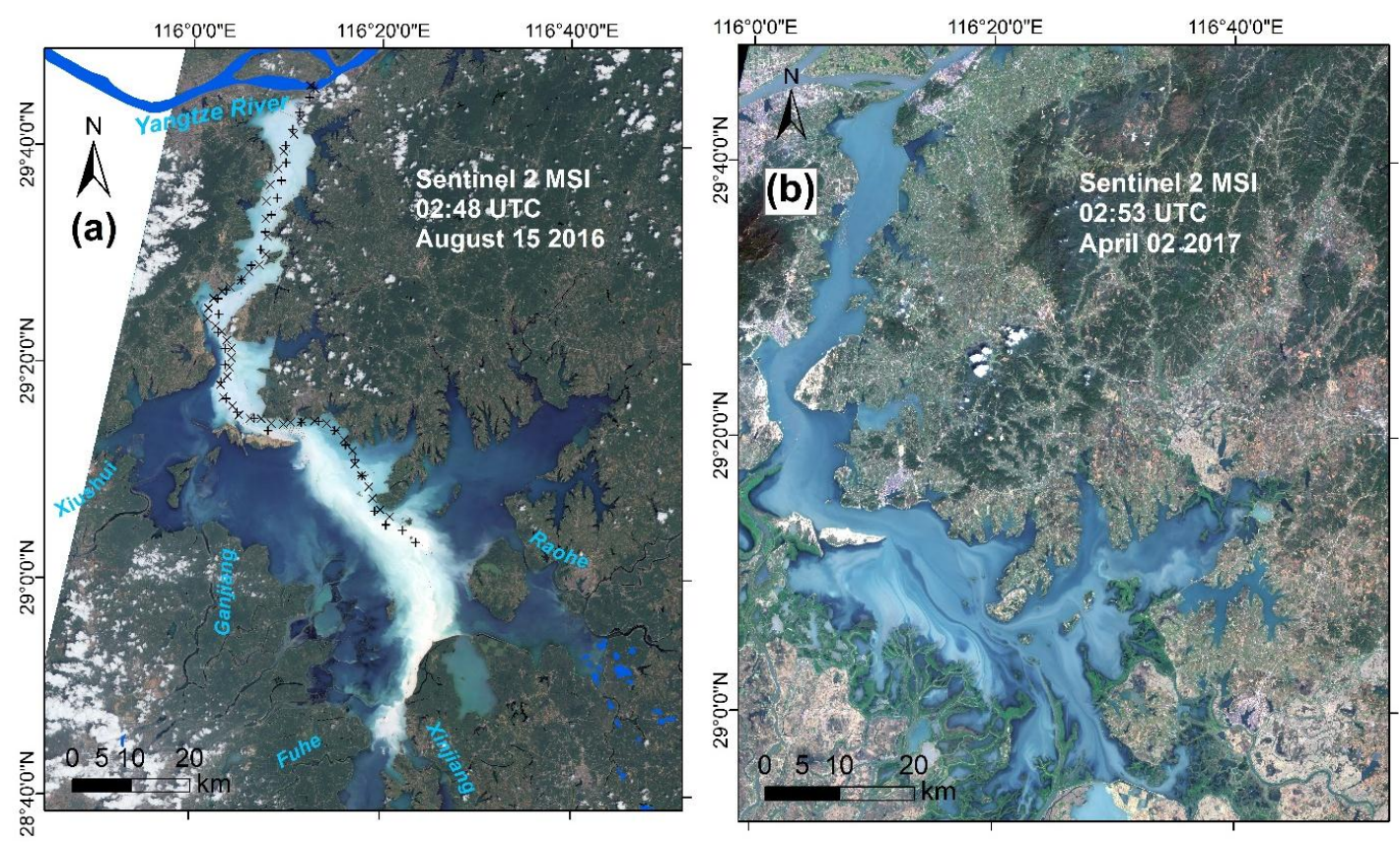

Figure 1. True color composite of atmospherically corrected Sentinel 2 MSI images captured on 15 August 2016 (a) and 2 April 2017 (b), respectively, showing Poyang Lake, and the sampling sites in $2010(\times)$ and $2011(+)$ are illustrated in (a).

\subsection{In-Situ Data}

Fieldworks were carried out on 16-18 October 2010 and 8-10 August 2011. Eighty-five sampling sites (47 in 2010 and 38 in 2011) were distributed along the main channel of Poyang Lake (Figure 1a). At each sampling site, the wind speed and direction were measured using a wind velocity indicator to determine the water-air interface reflectance rate used in remote sensing reflectance calculation. The location was recorded using a global positioning system receiver (Garmin Ltd., Lenexa, KS, USA). Water spectra were measured using a portable ASD Fieldspec Pro Dual VNIR spectrometer (ASD Inc., Longmont, CO, USA). The ASD Fieldspec Pro Dual VNIR spectrometer has a spectral range of 350-1050 nm with a spectral sampling interval of $1.4 \mathrm{~nm}$, and it was used to measure the water spectra following the Ocean Optics Protocols For Satellite Ocean Color Sensor Validation [38] and steps described by Ma et al. [39].

The $C_{\mathrm{SPM}}$ value of each water sample was measured gravimetrically with steps: (1) the water sample was filtered using a pre-dried and weighted Whatman GF/F glass fiber filter with a $0.45 \mu \mathrm{m}$ pore size; (2) the filter was dried for $2 \mathrm{~h}$ at $110{ }^{\circ} \mathrm{C}$ and reweighted after cooling to room temperature; 
and (3) the $C_{\text {SPM }}$ was obtained by dividing the difference in weight before and after filtering by the water sample volume [39].

\subsection{Satellite Images and Pre-Processing}

\subsubsection{Satellite Images}

The Sentinel 2 MSI, with a $290 \mathrm{~km}$ field of view and a radiometric quantization of 12-bit, provides a total of 13 spectral bands spanning from visible and near infrared to SWIR spectral region, and it has four bands with a spatial resolution of $10 \mathrm{~m}$, six bands with $20 \mathrm{~m}$, and three bands with $60 \mathrm{~m}$ [40]. Two Sentinel 2 MSI L1C images captured on 15 August 2016 and 2 April 2017 were downloaded from the website provided by European Space Agency (https://scihub.copernicus.eu/dhus/). The inundation areas of Poyang Lake were appropriately 3200 and $1700 \mathrm{~km}^{2}$ on 15 August 2016 and 2 April 2017, respectively, which represent the characteristics of Poyang Lake in the wet season and in the dry season.

One MODIS Terra image captured on 15 August 2016 and one MODIS Aqua L1A image captured on 2 April 2017 were downloaded from NASA OceanColor website (http:/ / oceancolor.gsfc.nasa.gov/). The MODIS Terra image, instead of MODIS Aqua, was used for the MODIS Aqua image on 15 August 2016 because it was affected by clouds. The MODIS images were atmospherically corrected by firstly removing the Rayleigh reflectance and then subtracting the reflectance at $1240 \mathrm{~nm}$ following the procedures applied by Wu et al. [12]. The Sentinel 2 MSI images were resampled to $20 \mathrm{~m}$ to facilitate further processing and analyses.

\subsubsection{Sentinel 2 MSI Atmospheric Correction}

Sentinel 2 MSI L1C product provides the top of atmosphere reflectance $\left(\rho_{T O A}\right)$, which is assumed to be the sum of Rayleigh reflectance $\left(\rho_{r}\right)$, aerosol reflectance $\left(\rho_{a}\right)$ and water-leaving reflectance $\left(\rho_{w}\right)$ :

$$
\rho_{T O A}=\rho_{r}+\rho_{a}+t \cdot \rho_{w}
$$

where $t$ is the two-way diffuse atmospheric transmittance [41].

The reflectance caused by Rayleigh scattering was estimated with the $6 \mathrm{~S}$ radiative transfer code [42] for each band, meanwhile the diffuse atmospheric transmittance $(t)$ was also derived. A mid-latitude Summer atmosphere condition was adopted, and the mean values of solar and view zenith and azimuth across the whole granule were calculated for the sun and sensor geometry. Cloud and land masking was performed with a threshold on the reflectance centered at $1610 \mathrm{~nm}$, and pixels were classified as not being water when the Rayleigh-corrected reflectance $\left(\rho_{c}=\rho_{T O A}-\rho_{r}\right)$ of B11 was greater than $0.0215[28,43]$.

The SWIR-based aerosol correction method $[28,44]$ was implemented using the following steps: (1) a $15 \times 15$ moving average filter was applied to improve the SNR of two SWIR bands; (2) the aerosol type $(\varepsilon)$ was determined from the ratio of two SWIR bands $\left(\varepsilon=\rho_{c}{ }^{11} / \rho_{c}{ }^{12}\right)$ for each pixel; (3) the $\varepsilon^{i, 12}$ of a given band $i$ over band 12 was extrapolated exponentially as follow:

$$
\varepsilon^{i, 12}=(\varepsilon)^{\delta i} \text { and } \delta i=\frac{\lambda_{12}-\lambda_{i}}{\lambda_{12}-\lambda_{11}}(\lambda \text { is the wavelength }) ;
$$

and (4) the $\rho_{w}$ at the $i^{\text {th }}$ band was derived with the following formula:

$$
\rho_{w}^{i}=\frac{1}{t^{i}}\left(\rho_{c}^{i}-\varepsilon^{i, 12} \cdot \rho_{c}^{12}\right)
$$

where $t^{i}$ is the two-way diffuse atmospheric transmittance for band $i$. 


\subsection{In-Situ Water-Leaving Reflectance Calculation}

The abnormal radiance measurements from grey diffuse reflectance standard, water, and sky were first removed considering their spectral characteristics, and the remote sensing reflectance for each sampling site was then calculated using the remaining measurements with the following equation [39]:

$$
R_{\mathrm{rs}}=\frac{L_{w}-r L_{s k y}}{\pi L_{p} / \rho_{p}}
$$

where the $R_{\mathrm{rs}}\left(\mathrm{sr}^{-1}\right)$ is the remote sensing reflectance; $L_{w}, L_{s k y}$ and $L_{p}\left(\mathrm{~W} \cdot \mathrm{m}^{-2} \cdot \mathrm{sr}^{-1}\right)$ are the measured radiances from water, sky, and grey diffuse reflectance standard, respectively; $r$ indicates water-air interface reflectance rate, and its value is $0.022,0.025$, or 0.028 for a wind velocity of 0,5 , or $10 \mathrm{~m} / \mathrm{s}$, respectively; $\rho_{p}$ is the reflectance rate of grey diffuse reflectance standard, and its value is 0.25 ; and $\pi$ (sr) is solid angle. Only the $R_{\mathrm{rs}}$ at the wavelengths of $400-920 \mathrm{~nm}$ were employed for further analysis because of low SNR in the edges of the spectral regions and strong absorptions in longer spectral regions.

\subsection{Sentinel 2 MSI Spectral Simulation}

The in-situ $R_{\mathrm{rs}}$ spectra were integrated using the relative spectral response (RSR) function of Sentinel 2 MSI (downloaded from the website provided by European Space Agency, https:/ / earth.esa. $\mathrm{int} / \mathrm{web} /$ sentinel/user-guides/sentinel-2-msi/document-library; accessed on 4 July 2017) to obtain simulated water-leaving reflectance according to following formula:

$$
\rho_{w}=\pi \frac{\int_{\lambda_{1}}^{\lambda_{2}} R S R(\lambda) R_{r s}(\lambda) d \lambda}{\int_{\lambda_{1}}^{\lambda_{2}} R S R(\lambda) d \lambda}
$$

where $\lambda$ is the wavelength, $\lambda_{1}$ and $\lambda_{2}$ are the lower and upper wavelength bound for each band and $\rho_{w}$ is the simulated water-leaving reflectance. The $\rho_{w}$ values of the first nine bands were obtained for Sentinel 2 MSI.

\subsection{Model Development}

The samples with incorrect spectrum (non-typical case-II water spectrum or negative values), wrong water constituent concentration (negative value), or unstable measurement conditions were removed. The remaining samples were recorded and numbered from 1 to $\mathrm{n}$ based on $C_{\mathrm{SPM}}$ value from high to low. The odd-numbered samples were used for model calibration, the others for model validation. The $C_{\mathrm{SPM}}$ values of both datasets were statistically described. The $R_{\mathrm{rs}}$ spectra were visualized and analyzed. The correlation analysis between $C_{\mathrm{SPM}}$ and $R_{\mathrm{rs}}$ was implemented. The widely used linear, quadratic, exponential, and power models of $C_{\text {SPM }}$ against the simulated $\rho_{w}$ spectra were calibrated using the least squares technique, respectively. The calibrated models were applied to estimate the $C_{\mathrm{SPM}}$ values of validation dataset. The coefficient of determination $\left(\mathrm{R}^{2}\right)$, mean absolute percentage error (MAPE), and root mean square error (RMSE) between the measured and estimated values were calculated to assess the fitting and validation accuracy. Six models with better fitting and validation accuracies were selected for further analyses.

\subsection{CSPM Estimation and Comparison}

The selected six $C_{\text {SPM }}$ retrieval models were applied to Sentinel 2 MSI images to retrieve $C_{\text {SPM }}$ values. To evaluate these models' applicability, the $C_{\text {SPM }}$ values deriving from MODIS using an empirical model were used as the quasi-reference values and compared with those deriving from Sentinel 2. The $C_{\mathrm{SPM}}$ retrieval model based on MODIS B1 $\left(C_{\mathrm{SPM}}=0.43 \times \exp (31.46 \times \mathrm{B} 1), \mathrm{B} 1\right.$ is centered at $645 \mathrm{~nm}$ ), which was calibrated and validated with synchronous satellite and in-situ observations [12], was applied to MODIS images to retrieve $C_{\text {SPM }}$ values. The $C_{\text {SPM }}$ values derived from these sensors 
were mapped and compared to illustrate their consistence and difference. Moreover, the $C_{\mathrm{SPM}}$ values retrieved from each band of Sentinel 2 MSI were downsampled to $250 \mathrm{~m}$ by averaging, and plotted against those from MODIS. The correlation coefficient and simple linear regression line were calculated to evaluate the reliability of Sentinel 2 MSI-derived $C_{S P M}$ values. For expression convenience, MODIS was used to represent MODIS Terra and Aqua B1 in the following sections, since only this band was used for $C_{\text {SPM }}$ retrieval from MODIS images.

The image processing and mapping were implemented with Python and ArcGIS (ESRI, Inc., Redlands, CA, USA), except that the Rayleigh correction for MODIS images was carried out using SEADAS (http:/ / seadas.gsfc.nasa.gov/). Model calibration and validation were implemented using Matlab (Mathworks, Inc., Natick, MA, USA).

\section{Results}

\subsection{In-Situ Data}

Thirteen samples in 2010 were removed from following statistics and analyses, one with a negative $C_{\mathrm{CHL}}$ value, one with obviously higher reflectance than others, one with extremely low reflectance, and 10 collected under high wind velocities $(>5 \mathrm{~m} / \mathrm{s})$ or unstable light illumination condition on 15 October 2010. Four samples in 2011 were identified from their spectral shape and removed.

After removing outliers, a total of 68 in-situ samples were left. The statistical results (Table 1 ) for $C_{\text {SPM }}$ showed that the $C_{\text {SPM }}$ values of all the samples have a mean value of $77.75 \mathrm{mg} / \mathrm{L}$, a standard deviation of $60.56 \mathrm{mg} / \mathrm{L}$ and a coefficient of variation of $77.89 \%$, with the $C_{\mathrm{SPM}}$ ranging from 17.16 to $294.50 \mathrm{mg} / \mathrm{L}$. The calibration dataset (average $C_{\mathrm{SPM}}=79.45 \mathrm{mg} / \mathrm{L}$, standard deviation $=63.22 \mathrm{mg} / \mathrm{L}$, $\mathrm{CV}=79.57 \%$ ) and validation dataset (average $C_{\mathrm{SPM}}=76.05 \mathrm{mg} / \mathrm{L}$, standard deviation $=58.67 \mathrm{mg} / \mathrm{L}$, $\mathrm{CV}=77.15 \%$ ) hold similar statistical characteristics.

Table 1. Statistics describing the concentrations of suspended particulate matter $\left(C_{\mathrm{SPM}}, \mathrm{mg} / \mathrm{L}\right)$ of the calibration and validation dataset as well as all the samples. Std. Dev. means standard deviation, and $\mathrm{CV}$ is coefficient of variation (\%).

\begin{tabular}{ccccccc}
\hline Dataset & Number & Minimum & Maximum & Average & Std. Dev. & CV \\
\hline Calibration & 34 & 19.00 & 294.50 & 79.45 & 63.22 & 79.57 \\
Validation & 34 & 17.16 & 282.25 & 76.05 & 58.67 & 77.15 \\
All & 68 & 17.16 & 294.50 & 77.75 & 60.56 & 77.89 \\
\hline
\end{tabular}

The $R_{\mathrm{rs}}$ spectra show typical spectral characteristics of case-II waters (Figure 2a), in which $R_{\mathrm{rs}}$ values increase over $400-550 \mathrm{~nm}$ and are much higher than zero in NIR spectral regions. Normally, a higher $C_{\text {SPM }}$ value tends to produce a higher reflectance curve. There are two SPM reflectance peaks around 580 and $810 \mathrm{~nm}$. Figure $2 \mathrm{~b}$ shows the correlations between $C_{\mathrm{SPM}}$ and $R_{\mathrm{rs}}$ of all samples as well as samples with $C_{\mathrm{SPM}}$ greater than and lower than $50 \mathrm{mg} / \mathrm{L}$. When taking all samples into consideration, there exists significantly positive correlations between $C_{\mathrm{SPM}}$ and $R_{\mathrm{rs}}$ over $400-920 \mathrm{~nm}$ $(\mathrm{r}>0.6)$ and strong correlations between 707-900 $\mathrm{nm}(\mathrm{r} \geq 0.85)$ at a significance level of 0.05 (Figure 2b). For samples with $C_{\mathrm{SPM}}$ greater than $50 \mathrm{mg} / \mathrm{L}$, the correlations were obviously lower in visible spectral region and higher in NIR spectral region than those with $C_{\text {SPM }}$ greater than $50 \mathrm{mg} / \mathrm{L}$. However, all of the correlation curves peaked at around $750 \mathrm{~nm}$. 

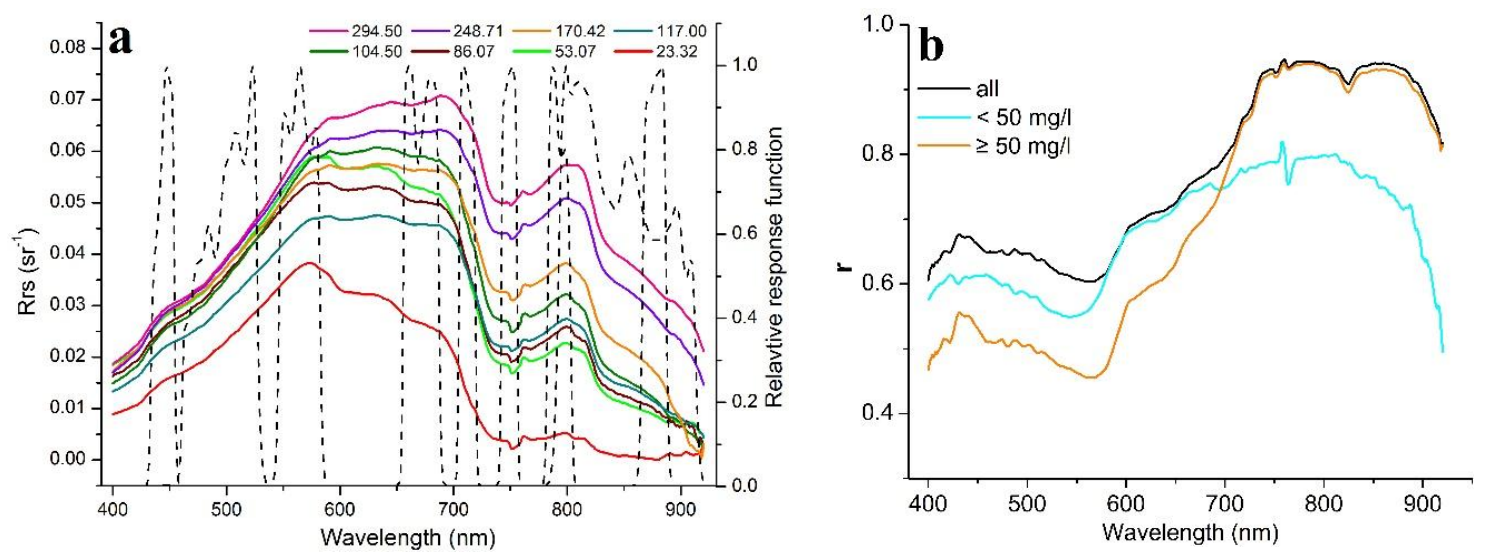

Figure 2. Remote sensing reflectance $\left(R_{\mathrm{rs}}\right)$ spectra and their corresponding suspended particulate matter concentrations $(\mathrm{mg} / \mathrm{L})$, and the relative spectral response function of the Sentinel 2 MSI (black dash curve) (a); and the correlation coefficient (r) between the $R_{\mathrm{rs}}$ and suspended particulate matter concentration $\left(C_{\mathrm{SPM}}\right)(\mathbf{b})$.

\subsection{Model Development}

The calibration results of $C_{\mathrm{SPM}}$ retrieval models are shown in Table 2, and the B4- and B7-based models are illustrated in Figure 3. The models based on Sentinel 2 MSI B6 or longer wavelengths achieved very good fitting performance with $\mathrm{R}^{2}$ over 0.9 , RMSE less than $20 \mathrm{mg} / \mathrm{L}$, and F-value of the model's significance test ranging from 151.14 to 205.49. The B7-based power model had the best fitting accuracy $\left(\mathrm{R}^{2}=0.93, \mathrm{MAPE}=16.58 \%, \mathrm{RMSE}=16.50 \mathrm{mg} / \mathrm{L}, \mathrm{F}=205.49\right)$. The B4-based exponential model explained $81 \%$ of the variation of $C_{\text {SPM }}$ with a RMSE value of $27.95 \mathrm{mg} / \mathrm{L}$ and a MAPE value of $30.32 \%$, while B5-based model produced better calibration accuracy $\left(R^{2}=0.88\right.$, MAPE $=20.99 \%$, RMSE $=21.51 \mathrm{mg} / \mathrm{L}$, $\mathrm{F}=114.47)$. However, B1-, B2- and B3-based models produced poor fitting accuracy with $\mathrm{R}^{2}$ smaller than 0.60. Therefore, the models calibrated with $\mathrm{B} 4-\mathrm{B} 8 \mathrm{~b}$ were selected for further validations.

Table 2. Regression models with the goodness of fitting between suspended particulate matter concentration $\left(C_{\mathrm{SPM}}, \mathrm{mg} / \mathrm{L}\right)$ and the simulated water-leaving reflectance at Sentinel-2 MSI B1-B8b.

\begin{tabular}{|c|c|c|c|c|}
\hline Model & $\mathbf{R}^{2}$ & MAPE & RMSE & $\mathbf{F}$ \\
\hline$C_{\mathrm{SPM}}=2.335 \times \exp (47.62 \times \mathrm{B} 1)$ & 0.57 & 40.89 & 41.02 & 20.24 \\
\hline$C_{\mathrm{SPM}}=1.769 \times \exp (37.38 \times \mathrm{B} 2)$ & 0.56 & 41.36 & 41.87 & 18.81 \\
\hline$C_{\mathrm{SPM}}=1.808 \times \exp (25.08 \times \mathrm{B} 3)$ & 0.53 & 38.34 & 42.83 & 17.29 \\
\hline$C_{\mathrm{SPM}}=4.044 \times \exp (19.53 \times \mathrm{B} 4)$ & 0.81 & 30.32 & 27.95 & 61.47 \\
\hline$C_{\mathrm{SPM}}=8.385 \times \exp (16.49 \times \mathrm{B} 5)$ & 0.88 & 20.99 & 21.51 & 114.47 \\
\hline$C_{\mathrm{SPM}}=3329 \times \mathrm{B} 6^{1.375}$ & 0.91 & 16.61 & 18.20 & 151.14 \\
\hline$C_{\mathrm{SPM}}=2950 \times \mathrm{B}^{1.357}$ & 0.93 & 16.58 & 16.50 & 205.49 \\
\hline$C_{\mathrm{SPM}}=2887 \times \mathrm{B}^{1.223}$ & 0.91 & 16.23 & 18.14 & 167.15 \\
\hline$C_{\mathrm{SPM}}=2520 \times \mathrm{B} \mathrm{b}^{1.42}$ & 0.90 & 18.30 & 19.59 & 141.14 \\
\hline
\end{tabular}

Note: MAPE is mean absolute percentage error (\%), RMSE is the root mean square error (mg/L), F is the F-value of the model's significance test.

The six selected models were applied to the validation dataset to estimate the $C_{S P M}$ values, and validation results were shown in Figure 4. Similar to the calibration results, the B6 or longer wavelength-based models produced better estimation accuracies, which explained $88-93 \%$ of the variation of measured $C_{\mathrm{SPM}}$, and the B7-based model produced the best validation performance $\left(\mathrm{R}^{2}=0.93, \mathrm{MAPE}=21.54 \%, \mathrm{RMSE}=16.06 \mathrm{mg} / \mathrm{L}\right)$. The B4-based model had the lowest estimation accuracy among the six selected, however, it still obtained acceptable performance $\left(R^{2}=0.77\right.$, MAPE $=36.87 \%$, RMSE $=32.38 \mathrm{mg} / \mathrm{L}$ ). Therefore, all the six selected models were applied to retrieve $C_{\mathrm{SPM}}$ values of Poyang Lake. 

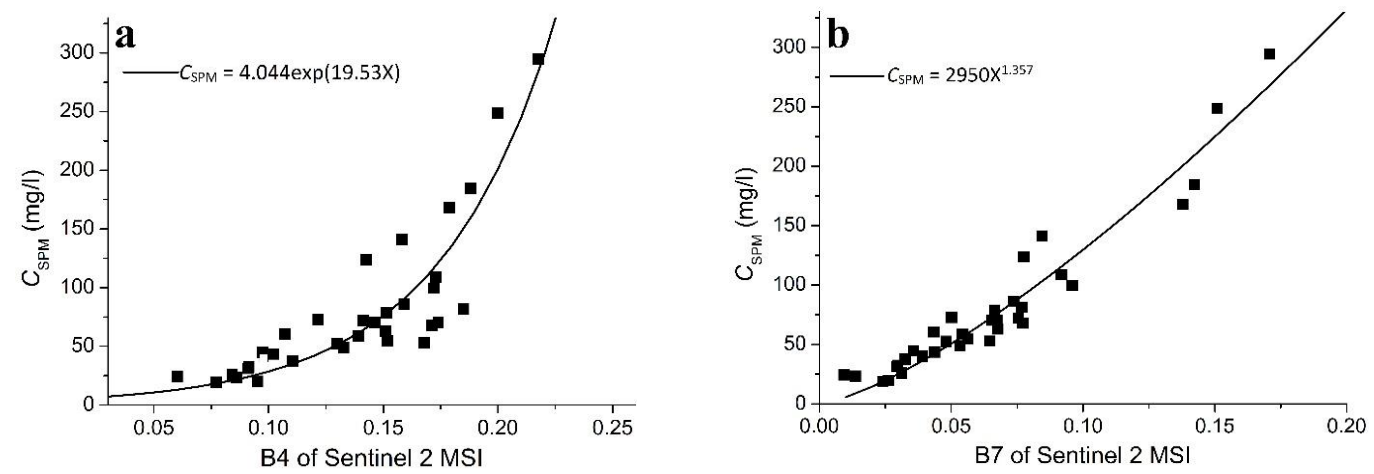

Figure 3. Suspended particulate matter concentration $\left(C_{\text {SPM }}\right)$ retrieval models based on Sentinel 2 MSI B4 (a) and B7 (b).
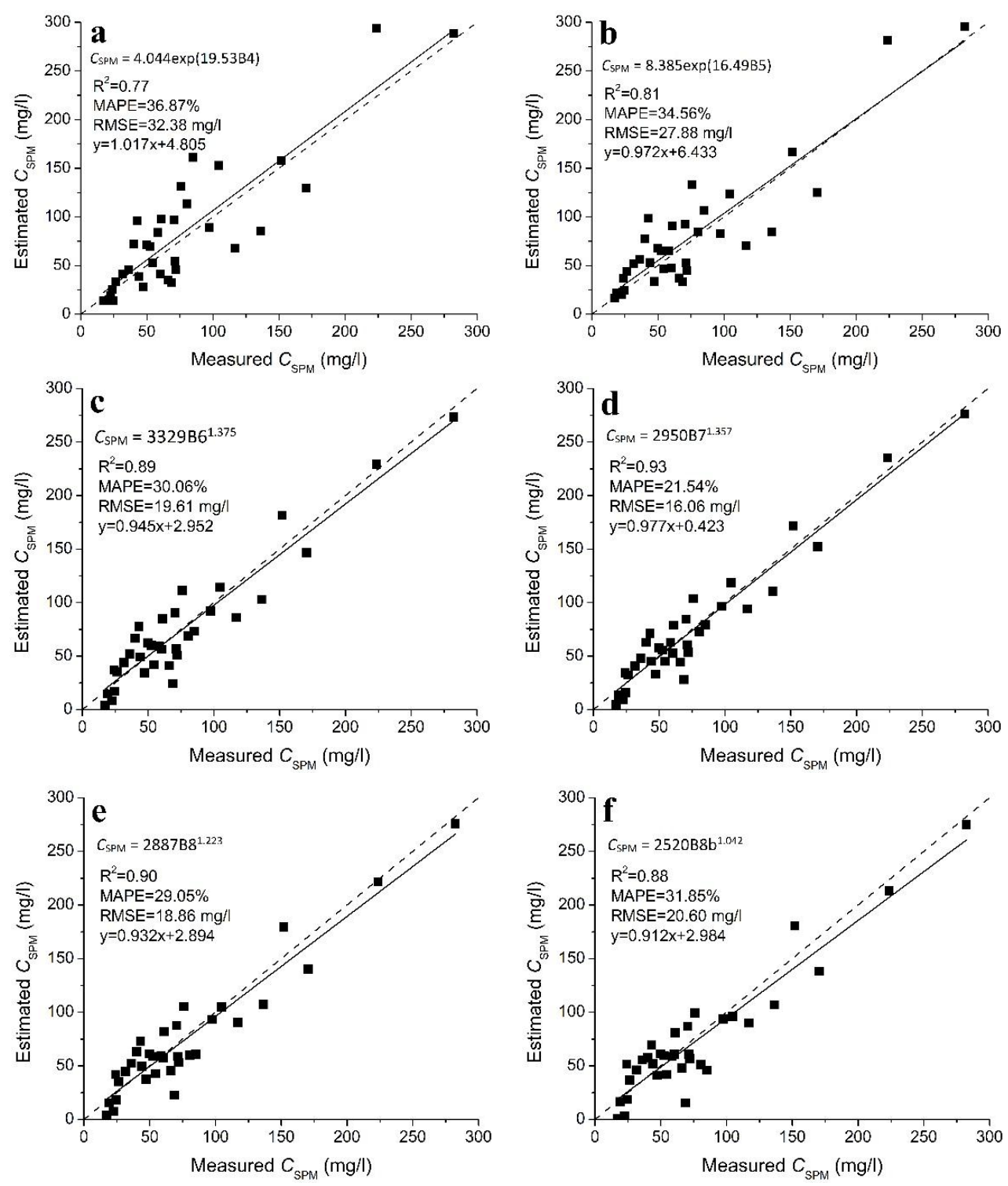

Figure 4. Scatter plots of estimated against measured suspended particulate matter concentration $\left(C_{\mathrm{SPM}}\right)$ for the validation dataset: Sentinel 2 MSI B4 (a), B5 (b), B6 (c), B7 (d), B8 (e), and B8b (f). The solid line is the regression line between the estimated and measured values, and the dashed line is $1: 1$ line. 


\section{3. $C_{S P M}$ Estimation and Comparison}

The $C_{\mathrm{SPM}}$ values derived from Sentinel 2 MSI B4, B7, and B8b, as well as those from MODIS captured on 15 August 2016 were shown in Figure 5. The distribution patterns of $C_{\mathrm{SPM}}$ obtained from the three bands of Sentinel 2 MSI and MODIS Terra were generally consistent across the whole Poyang Lake, while Sentinel 2, with obviously higher spatial resolutions, could resolve more detailed spatial variations than MODIS. The eastern and western parts of the lake had lower $C_{\text {SPM }}$ values, while a turbid plume with high loadings of $C_{\mathrm{SPM}}$ was observed in the middle part from south to north. However, the Sentinel 2 MSI B4 tended to produce slight lower $C_{\text {SPM }}$ values than the other three maps in the very high $C_{\mathrm{SPM}}$ regions, while the $\mathrm{B} 8 \mathrm{~b}$-derived map showed noise patterns in waters with low $C_{\mathrm{SPM}}$ values.
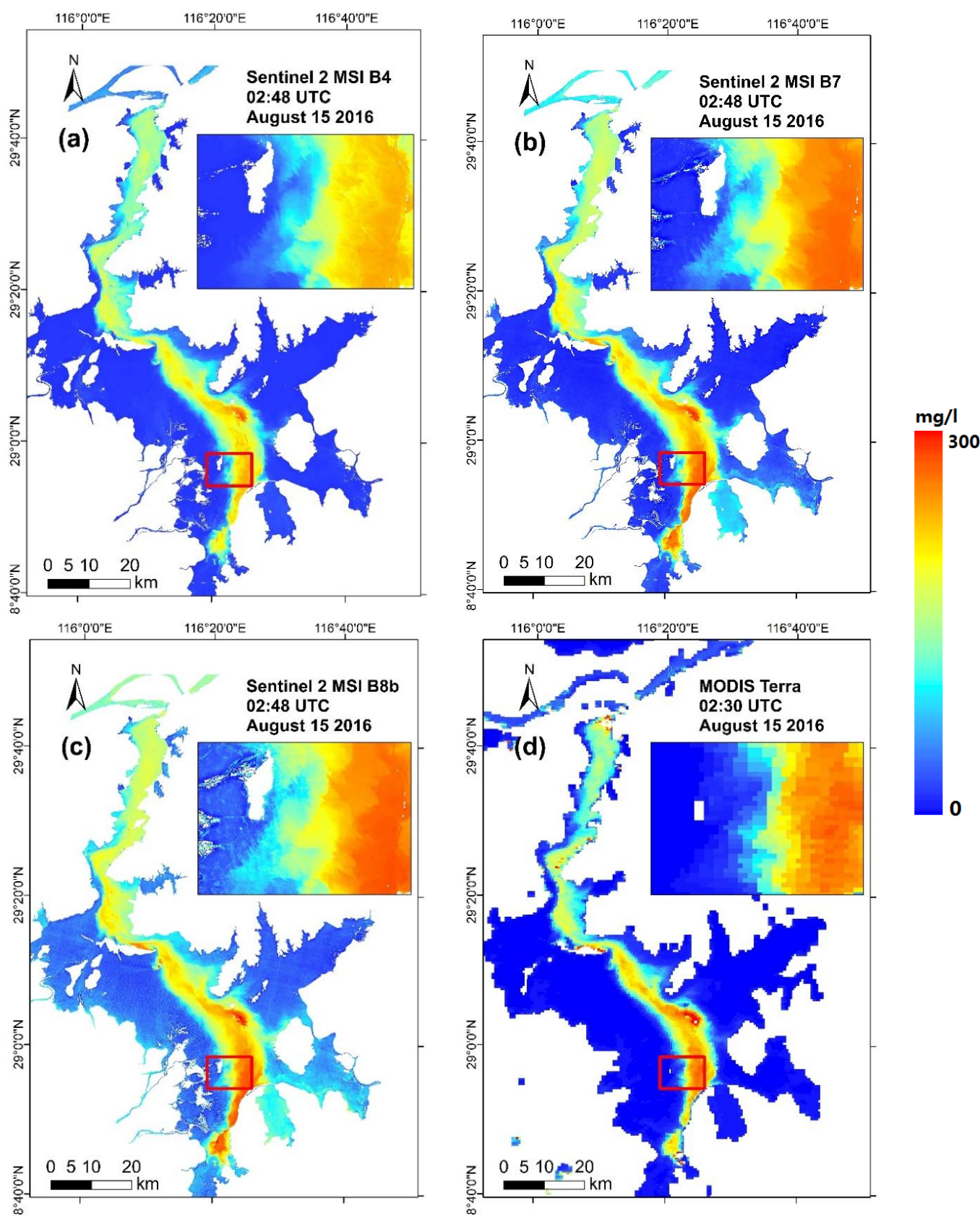

Figure 5. Suspended particulate matter concentrations $\left(C_{\mathrm{SPM}}\right)$ retrieved from Sentinel 2 MSI B4 (a), B7 (b), B8b (c), and MODIS Terra B1 (d) captured on 15 August 2016. The areas in the red rectangle are zoomed in to show the detailed $C_{\mathrm{SPM}}$ variations. 
Figure 6 shows the scatter plots of the $C_{\mathrm{SPM}}$ values derived from Sentinel 2 MSI B4-B8b against

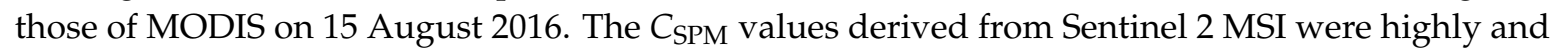
significantly correlated with those from the MODIS at a significance level of $0.05(\mathrm{r}>0.9, p<0.05)$, however, the slope of the regression line varied a lot. The slope of the regression line for Sentinel 2 MSI B4 and B5 against MODIS were 0.76 and 0.75, respectively, which means that these two bands tended to produce lower $C_{\mathrm{SPM}}$ values than MODIS for high $C_{\mathrm{SPM}}$ values. However, the $C_{\mathrm{SPM}}$ values retrieved from Sentinel 2 MSI B6-B8b are relatively more consistent with those from MODIS with a higher slope of the regression line between them. Overall, the Sentinel 2 MSI B7 showed the highest consistence with a slope of the regression line of 1.00 , though it tended to produce slightly higher $C_{\mathrm{SPM}}$ values than MODIS with an intercept of $9.87 \mathrm{mg} / \mathrm{L}$. Figure 7 illustrates the mean and standard deviation values of $C_{\text {SPM }}$ across the whole lake derived from Sentinel 2 MSI and MODIS. The mean $C_{\text {SPM }}$ values of Sentinel 2 MSI B4-B8b were 22.31, 28.10, 25.51, 29.86, 24.25, and $37.76 \mathrm{mg} / \mathrm{L}$, respectively, which were higher than that of MODIS $(19.51 \mathrm{mg} / \mathrm{L})$. The standard deviation values were obviously larger than their corresponding mean values except Sentinel 2 MSI B5, which indicates high spatial variations across the lake. The Sentinel 2 MIS B4 and B5 had lower standard variations than other bands.

The $C_{\text {SPM }}$ values derived from Sentinel 2 MSI B4, B7, and B8b as well as those from MODIS on 2 April 2017 were shown in Figure 8. The $C_{\text {SPM }}$ values were relatively low in most parts of Poyang Lake on 2 April 2017, except that the central to southern Poyang Lake showed slightly higher SPM loading. Sentinel 2 MSI B4 and B7 produced similar $C_{\text {SPM }}$ distribution patterns with MODIS. However, the B8b-derived maps showed noise patterns and obviously held higher $C_{\mathrm{SPM}}$ values than the other three maps. Figure 9 illustrates the scatter plots of $C_{\mathrm{SPM}}$ values derived from Sentinel 2 MSI B4-B8b against those of MODIS on 2 April 2017. The $C_{\text {SPM }}$ values derived from Sentinel 2 MSI were strongly and significantly correlated with those from the MODIS at a significance level of 0.05 $(\mathrm{r}>0.8, p<0.05)$, however, all of B4-B8b tended to produce higher $C_{\mathrm{SPM}}$ values than MODIS. Sentinel 2 MSI B4 showed the highest consistence with MODIS with a correlation coefficient of 0.91 , a slope of 0.97 , and an intercept of $6.42 \mathrm{mg} / \mathrm{L}$. Sentinel $2 \mathrm{MSI}$ B8b produced the lowest consistence with an intercept of $19.27 \mathrm{mg} / \mathrm{L}$, while B7 produced acceptable results with a correlation coefficient of 0.86 and a regression line of $y=1.11 x+7.63$ with MODIS. The mean and standard deviation values of $C_{\text {SPM }}$ values from Sentinel 2 MSI and MODIS were illustrated in Figure 10. Similar to results shown in Figure 9, the Sentinel 2 MSI B4 with mean $=13.43 \mathrm{mg} / \mathrm{L}$ and standard deviation $=5.21 \mathrm{mg} / \mathrm{L}$ was the closest to MODIS (mean $=7.19$, standard deviation $=4.87 \mathrm{mg} / \mathrm{L}$ ), while Sentinel $2 \mathrm{MSI}$ B8b produced an obviously higher mean value $(27.18 \mathrm{mg} / \mathrm{L})$ than the other bands. The low standard deviations, ranging from 4.87 to $6.48 \mathrm{mg} / \mathrm{L}$, also indicated low spatial variations of $C_{\text {SPM }}$ values on 2 April 2017. 

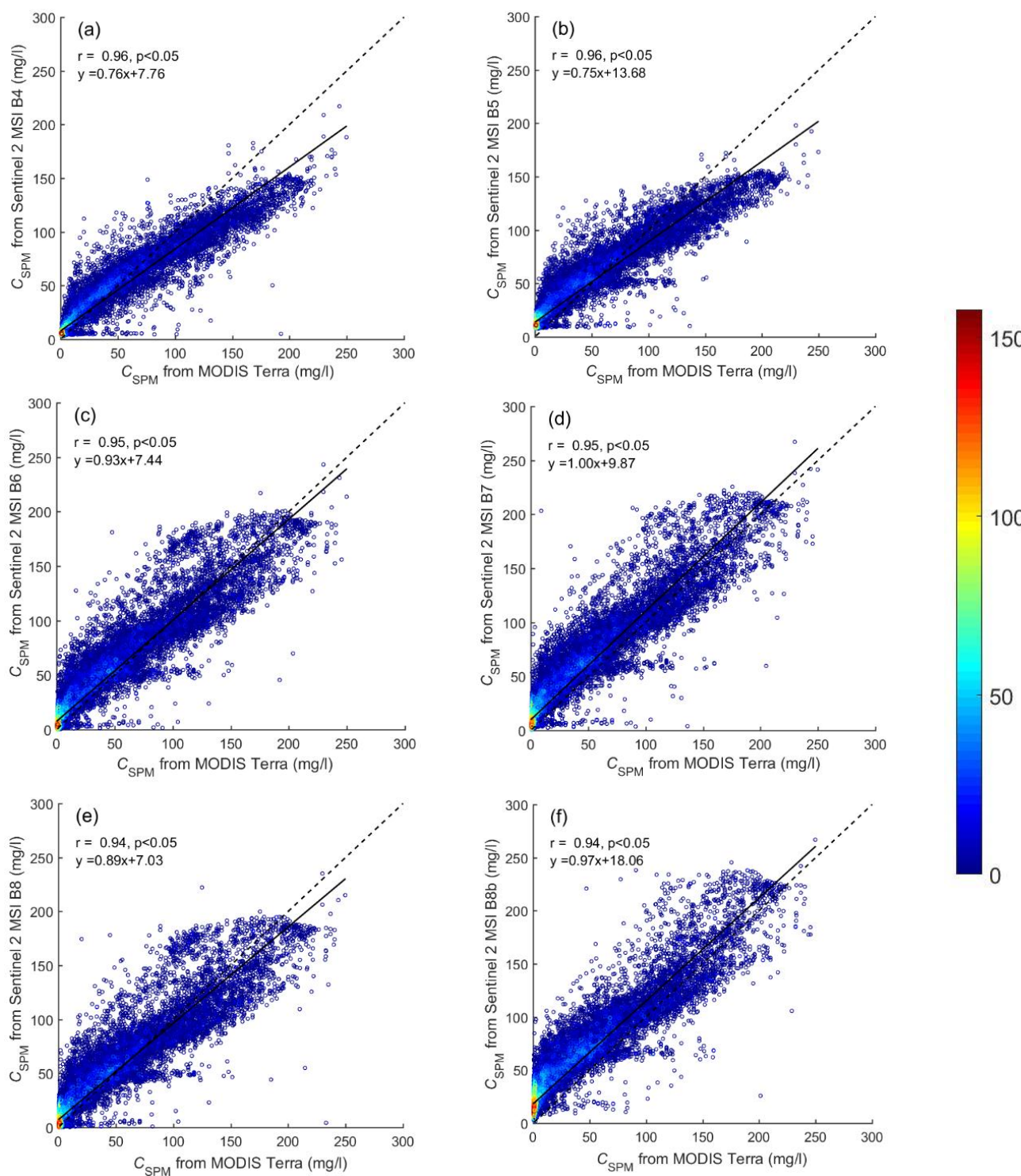

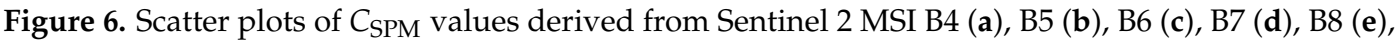
and B8b (f) against those from MODIS Terra B1 on 15 August 2016. The solid line is the regression line and the dashed line is 1:1 line. The number along the color ramp indicates the pixel number after $\log$ transformation $\left(\mathrm{y}=\log _{1.05}(\mathrm{x})\right)$.

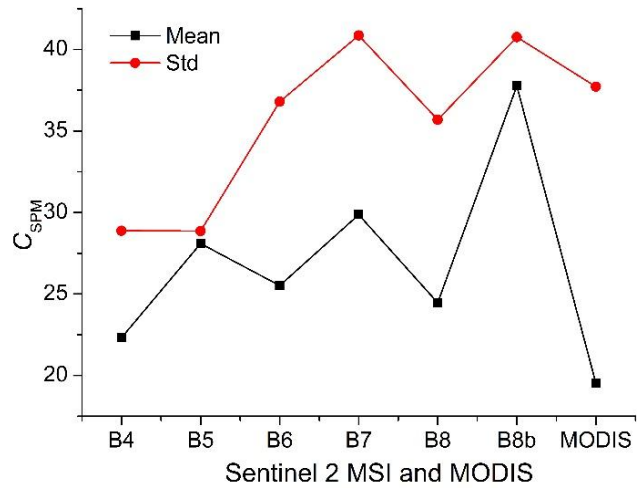

Figure 7. The mean and standard deviation (Std) of $C_{\text {SPM }}$ derived from Sentinel 2 MSI B4-B8b and MODIS Terra B1 on 15 August 2016. 

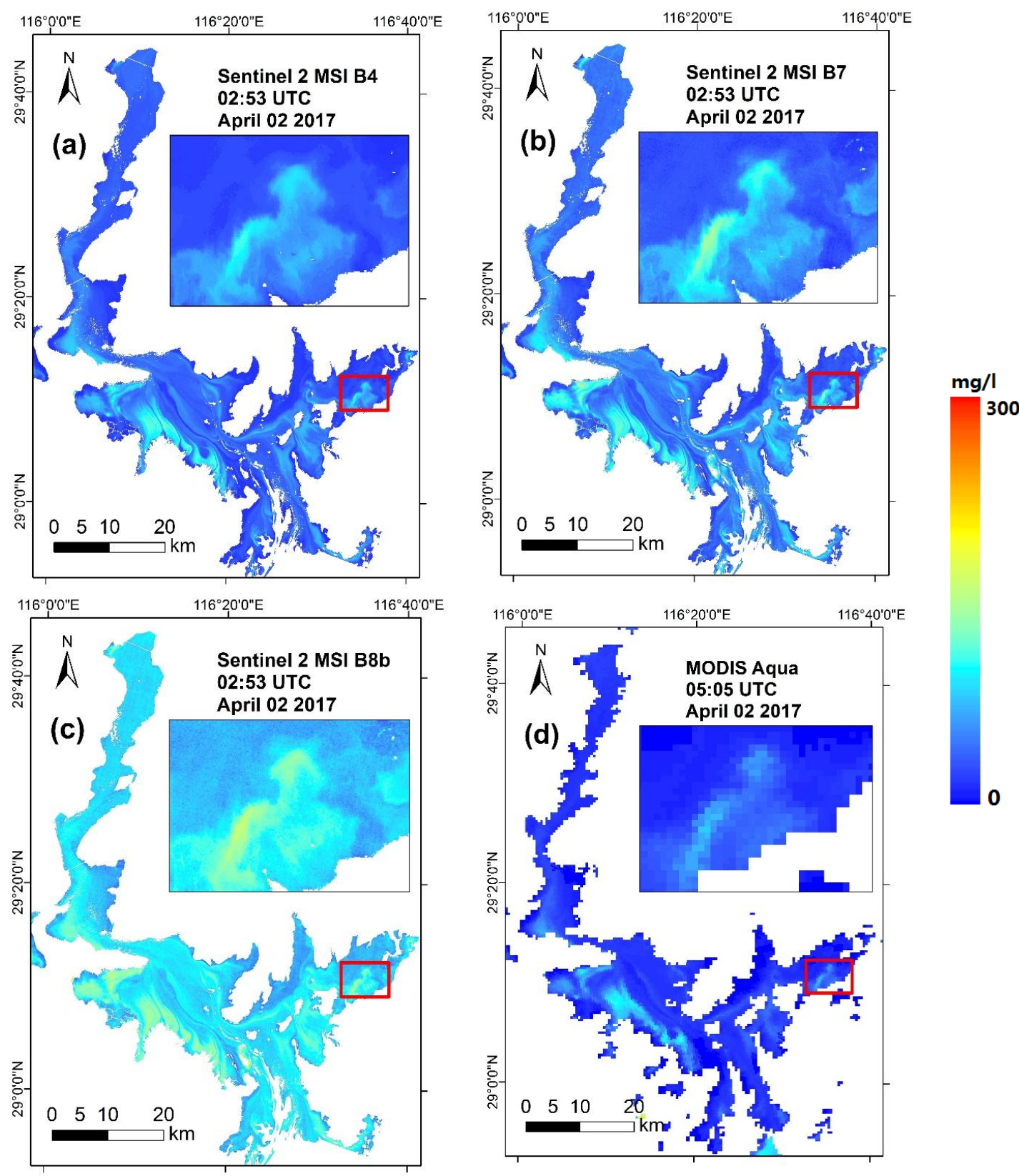

Figure 8. Suspended particulate matter concentrations ( $\left.C_{\text {SPM }}\right)$ retrieved from Sentinel 2 MSI B4 (a), B7 (b), B8b (c), and MODIS Aqua B1 (d) on 2 April 2017. The areas in the red rectangle are zoomed in to show the detailed $C_{\mathrm{SPM}}$ variations. 

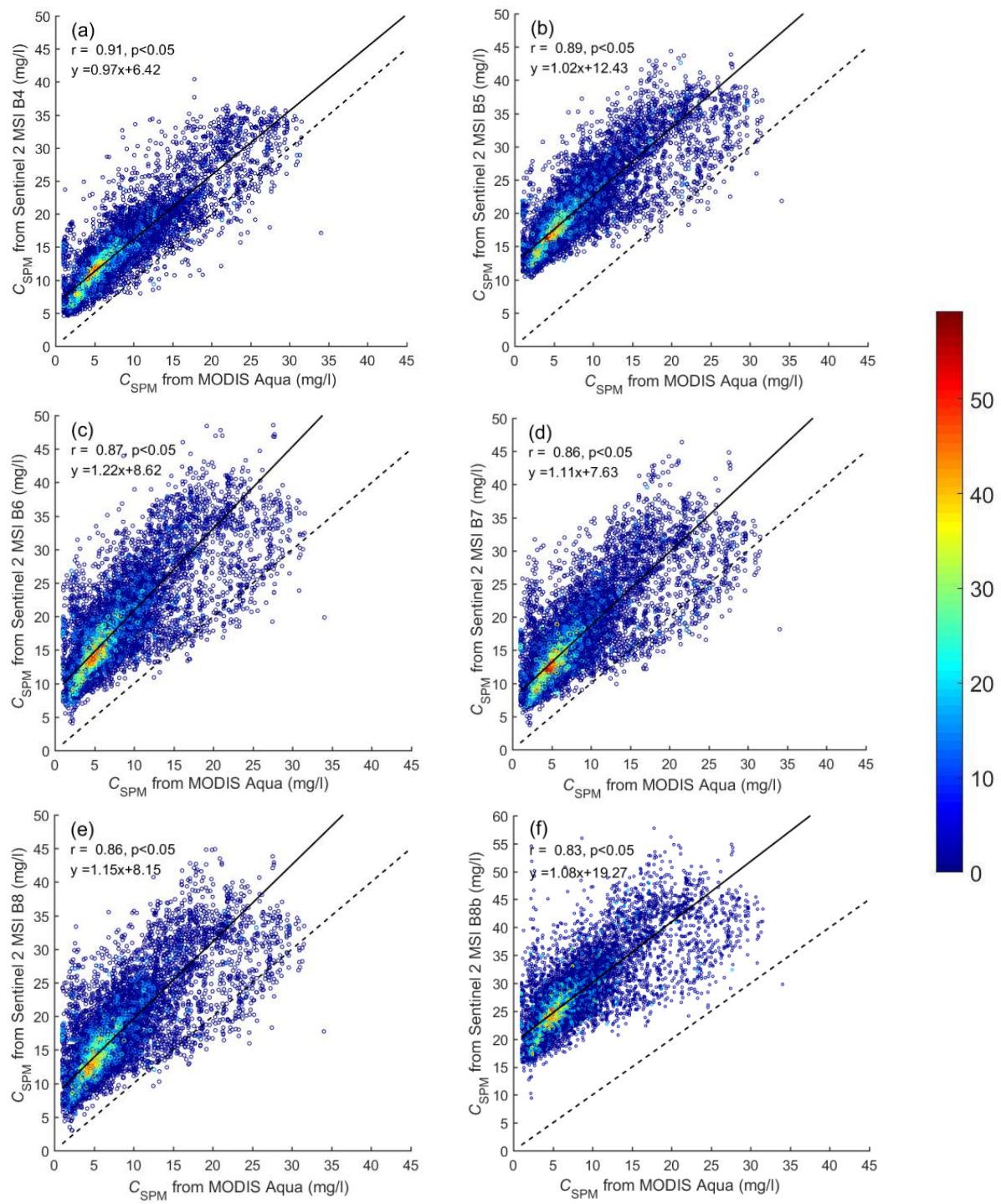

50

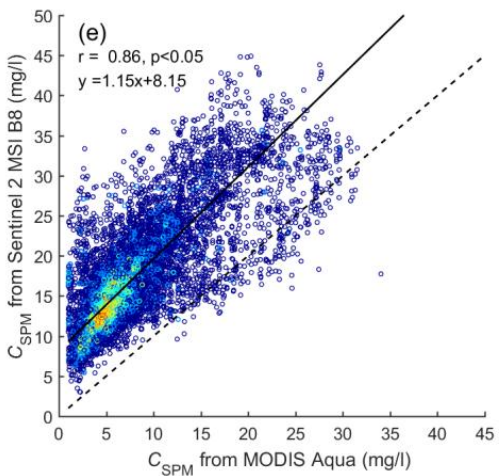

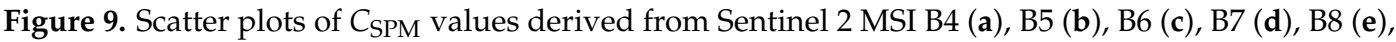
and B8b (f) against those from MODIS Aqua on 2 April 2017. The solid line is the regression line and the dashed line is 1:1 line. The number along the color ramp indicates the pixel number after $\log$ transformation $(\mathrm{y}=\log 1.05(\mathrm{x}))$.

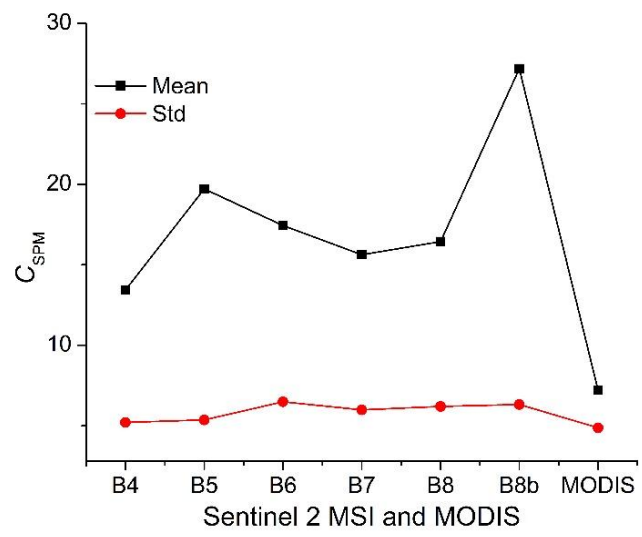

Figure 10. The mean and standard deviation (Std) of $C_{\text {SPM }}$ derived from Sentinel 2 MSI B4-B8b and MODIS Aqua B1 sensed on 2 April 2017. 


\section{Discussion}

This study developed $C_{\text {SPM }}$ retrieval models with simulated Sentinel 2 MSI spectra and in-situ $C_{\text {SPM }}$ values in Poyang Lake. Several models were reported with in-situ optical and $C_{\text {SPM }}$ values, and they were successfully applied to satellite images for $C_{\text {SPM }}$ retrieval $[14,45,46]$. The models developed in this study should be reliable considering the following two reasons: (i) the $R_{\mathrm{rs}}$ derived from in-situ measurements are less affected by atmospheric interference and are frequently used for spaceborne sensor calibration and validation [5,47], and the NASA protocol [38] was strictly followed to ensure high quality optical measurements; and (ii) the synchronous in-situ $C_{\mathrm{SPM}}$ values and $R_{\mathrm{rs}}$ are more consistent in spatial and temporal scale, while the spatiotemporal scale gap problem always exists between satellite and in-situ observations [3].

This study found that the Sentinel 2 MSI B4-B8b band obtained acceptable to high fitting accuracy and validation performance, and the models derived from Sentinel 2 MSI B1-B3 were less accurate. These calibration results were similar to the models develop for Dongting Lake [3], which is also a large sediment-laden floodpath lake along the middle section of the Yangtze River. According to the bio-optical model $[39,48], R_{\mathrm{rs}}$ can be expressed as a function of absorption and backscattering coefficients. The reflectance of short wavelength bands, like Sentinel 2 MSI B1-B3, are affected by the absorption and backscattering characteristics of the water optically active matters (including SPM, chlorophyll, and CDOM) and pure water together, therefore the correlations between $C_{\text {SPM }}$ and these three bands are weak (Figure 2). The absorption coefficients of these optically active matters decrease with increasing wavelength, and turn close to zero in NIR regions [49]. Therefore, the magnitude and shape of $R_{\mathrm{rs}}$ are mainly determined by the particulate backscattering coefficient and pure water absorption in longer spectral regions [50], which explains the better fitting results obtained by Sentinel 2 MSI B6-B8b. The best calibration and validation results obtained by Sentinel 2 MSI B7 (centered at $783 \mathrm{~nm}$ ) may be explained by the fact that it lies in the left shoulder of the SPM reflectance peak around $810 \mathrm{~nm}$ (Figure 2a), which is a result of particulate backscattering and slight decrease in water absorption [51]. Such a result is consistent with that of Kutser et al. [23], who demonstrated the capability of Sentinel 2 MSI B7 in retrieving $C_{\text {SPM }}$ values over strong absorbing black waters due to its adjacency to 810 reflectance peak.

The absorptions of the optically active matters could still contribute to the reflectance of Sentinel 2 MSI B4 (centered at $665 \mathrm{~nm}$ ), especially for waters with high loading of SPM or the presence of absorbing substances $[3,23]$. Therefore, the relationships between $C_{\mathrm{SPM}}$ and $R_{\mathrm{rs}}$ at this band are complicated, and the calibration samples scattered sparsely around the fitting curve in Figure 3, which explains the relatively lower performance obtained by Sentinel 2 MSI B4. Such a statement could also be supported by the findings of Wu et al. [49], in which an obvious phytoplankton absorption peak, a correlation peak between $\mathrm{a}_{\mathrm{d}}$ and suspended particulate inorganic matter concentration, and a correlation peak between $\mathrm{a}_{\mathrm{g}}$ and $C_{\mathrm{DOC}}$ were observed in this spectral region, while the correlation between $\mathrm{a}_{\mathrm{p}}$ and $C_{\mathrm{SPM}}$ plummeted around $665 \mathrm{~nm}$. However, Sentinel 2 MSI B4 still holds advantage for waters with low $C_{\mathrm{SPM}}$ values, which has been widely used for case-II waters $[13,16,25]$.

By applying the models calibrated in this study, the Sentinel 2 MSI B4-B8b produced generally consistent $C_{\mathrm{SPM}}$ maps with MODIS. However, compared with MODIS images, the most frequently used data for $C_{\text {SPM }}$ monitoring in Poyang Lake, Sentinel 2 MSI can resolve finer variations over small scales. It is understandable that one single MODIS pixel with a $250 \mathrm{~m}$ resolution is corresponding to more than $12 \times 12$ pixels with a $20 \mathrm{~m}$ resolution. Therefore, Sentinel 2 MSI can provide more accurate estimations especially in spatially heterogeneous regions. Similar phenomena were also found for Landsat 8 OLI and GF 1 WFV OLI over the MODIS Terra and Aqua [14,28,52]. More importantly for the floodpath lake, many parts of Poyang Lake can be narrow in dry seasons, which makes low resolution images unusable, while higher spatial resolution image, such as Landsat 8 OLI and Sentinel 2 MSI, can still work well to resolve small water bodies [53,54].

The Sentinel 2 MSI B8b (centered at $865 \mathrm{~nm}$ ) might not be suitable for $C_{\mathrm{SPM}}$ retrieval because of the noise patterns in the low $C_{\mathrm{SPM}}$ waters. This could be explained by the low $R_{\mathrm{rs}}$ for waters 
with low $C_{\mathrm{SPM}}$ values due to high water absorption in this band [55]. For example, a $R_{\mathrm{rs}}$ value of 0.00046 was measured at $865 \mathrm{~nm}$ for the water sample with a $C_{\mathrm{SPM}}$ value of $23.32 \mathrm{mg} / \mathrm{L}$. Therefore, the water-leaving radiances only contribute to a very small part of the satellite-sensed signal at this band, which could not be separated accurately from the atmospheric interference. Moreover, the relative lower SNR value held by Sentinel 2 MSI B8b may also partially account for the noise pattern.

The $C_{\mathrm{SPM}}$ values derived from MODIS were cross-compared with those from Sentinel 2 MSI to determine the reliability and applicability of Sentinel 2 MSI-based models developed in this study, because of lacking synchronous Sentinel image and in-situ $C_{\text {SPM }}$ values. The time differences between MODIS and Sentinel 2 MSI overpasses are within $3 \mathrm{~h}$. Therefore, it is reasonable to omit the influence of SPM loadings dynamics on cross-comparisons between Sentinel 2 and MODIS. The MODIS-based $C_{\text {SPM }}$ retrieval model was used because it was calibrated and validate with two independent datasets collected in 2007 and 2012, respectively, and found to have acceptable and stable performance [12]. Compared with MODIS, Sentinel 2 MSI B4 and B5 tended to underestimate in the regions with higher $C_{\text {SPM }}$ values, which might be partially explained by the models' uncertainty and the discrepancy in $R S R$ and SNR of the two sensors [14]. The Sentinel 2 MSI B7-derived $C_{\text {SPM }}$ values were the most consistent with those from MODIS for turbid waters, which further demonstrates its capability in $C_{\text {SPM }}$ retrieval for Poyang Lake. The cross-comparisons between MODIS and other sensors for $C_{\text {SPM }}$ retrieval could be found in literatures $[14,25]$. For examples, Wu et al. developed Landsat-5 TM-based $C_{\text {SPM }}$ model for Poyang Lake by assuming the MODIS-derived to be the true values [56]; and Tian et al. developed GF-1 WFV-based $C_{\text {SPM }}$ model for Deep Bay with assistance of MODIS-derived $C_{\text {SPM }}$ values [52].

The high quality SWIR bands of Sentinel 2 MSI also partially contributed to the successful $C_{S P M}$ retrieval in this study, because they facilitate the atmospheric correction over case-II waters like Poyang Lake. The SWIR-based atmospheric correction method has been proven to be reliable and integrated into SEADAS for the operational product generations over turbid waters from MODIS images [57,58]. Recently, it is also modified and successfully applied to Landsat 8 OLI, a precursor of Sentinel 2 MSI $[28,59,60]$. Although the Sentinel 2 MSI SWIR bands is about one third of the Landsat 8 OLI SWIR bands in terms of SNR specification, the SNR can be improved through average filtering [44]. Therefore, we infer that the SWIR-based atmospheric correction method should produce acceptable performance for Sentinel 2 MSI.

The advantage of high temporal resolution is obvious, since frequent observations would enable $C_{\mathrm{SPM}}$ monitoring over short periods. For example, GF 1 WFV with a 4-day revisit period obtained monthly cloud-free observations for Poyang Lake in 2015, while Landsat 8 OLI only had 4 clear scenes over the same period. Sentinel 2 MSI provides a revisit time of 5-day at the equator with the full operations of the two satellites [40]. Considering its capability in $C_{\text {SPM }}$ retrieval demonstrated in our study, Sentinel 2 MSI should be an ideal data source for the operational $C_{S P M}$ monitoring in Poyang Lake. Novoa et al. [53] developed a switching model for low-to-high turbidity waters, which used red band for low-to-medium turbid waters and NIR band for high turbid waters to retrieve $C_{\text {SPM }}$ values. Developing a switching model for Poyang Lake based on Sentinel 2 MSI B4 and B7 using this modeling strategy might work better to capture the complex spatiotemporal $C_{\text {SPM }}$ patterns of this floodpath lake. Moreover, further elaborate evaluation of the atmospheric correction and $C_{S P M}$ retrieval accuracy with concurrent in-situ and satellite observations would be a meaningful task.

\section{Conclusions}

The Sentinel 2 MSI B4-B8b-based CSPM retrieval models were developed, and they were found acceptable and applicable in estimating $C_{\text {SPM }}$ values of Poyang Lake. The Sentinel 2 MSI B4-B8b-derived $C_{\text {SPM }}$ maps revealed clear spatial distribution patterns, and a riverine induced turbid plume was observed on 15 August 2016, while the $C_{\text {SPM }}$ values were relatively lower across the whole Poyang Lake on 2 April 2017. The consistent results of cross comparisons between MODIS and Sentinel 2 MSI also proved the applicability of the models developed. The Sentinel 2 MSI B7-based power model $\left(C_{\mathrm{SPM}}=2950 \times B 7^{1.357}\right)$ with the highest calibration and validation accuracy, and high consistency 
with MODIS, is recommended for sediment-laden waters, while the Sentinel 2 MIS B4-based model $(4.044 \times \exp (19.53 \times \mathrm{B} 4))$ works better for clear waters. This study demonstrated that the Sentinel 2 MSI, with higher spatial resolution than MODIS, more band configurations than GF 1 WFV, and shorter revisiting time than Landsat 8 OLI, should be an appropriate data source for monitoring $C_{\mathrm{SPM}}$ over case-II waters such as Poyang Lake.

Acknowledgments: The research was supported by the Basic Research Program of Shenzhen Science and Technology Innovation Committee (No. JCYJ20151117105543692), Scientific Research Foundation for Newly High-End Talents of Shenzhen University, Natural Science Foundation of China (NSFC) General Research Grant (41471340), Shenzhen Future Industry Development Funding Program (No. 201507211219247860), Research Grants Council (RGC) of Hong Kong General Research Fund (GRF) (HKBU 203913) and Hong Kong Baptist University Faculty Research Grant (FRG2/14-15/073). We thank the Nanjing Institute of Geography and Limnology, Chinese Academy of Sciences for their help and assistance in the in-situ optical measurements and laboratory-based determinations. We are grateful to the two anonymous reviewers for their helpful comments and suggestion.

Author Contributions: All authors conceived and designed the study. Huizeng Liu, Shuibo Hu and Guofeng Wu made substantial contributions to experiments design. Huizeng Liu implemented the experiments. Teizhu Shi made substantial contributions to the field campaigns and spectral measurements. All authors discussed the basic structure of the manuscript, and Huizeng Liu finished the first draft. Qingquan Li, Qiming Zhou, Guofeng Wu, Shuibo Hu reviewed and edited the draft. All authors read and approved the submitted manuscript, agreed to be listed and accepted the version for publication.

Conflicts of Interest: The authors declare no conflict of interest.

\section{References}

1. Gordon, H.R.; Morel, A.Y. Remote Assessment of Ocean Color for Interpretation of Satellite Visible Imagery. Lect. Notes Coast. Estuar. Stud. 1983, 4, 375-387.

2. Duan, H.; Ma, R.; Zhang, Y.; Zhang, B. Remote-sensing assessment of regional inland lake water clarity in northeast China. Limnology 2009, 10, 135-141. [CrossRef]

3. Wu, G.; Cui, L.; Liu, L.; Chen, F.; Fei, T.; Liu, Y. Statistical model development and estimation of suspended particulate matter concentrations with Landsat 8 OLI images of Dongting Lake, China. Int. J. Remote Sens. 2015, 36, 343-360. [CrossRef]

4. Fischer, H.B.; List, J.E.; Koh, C.R.; Imberger, J.; Brooks, N.H. Mixing in Inland and Coastal Waters; Academic Press: San Diego, CA, USA, 1979.

5. Mouw, C.B.; Greb, S.; Aurin, D.; DiGiacomo, P.M.; Lee, Z.; Twardowski, M.; Binding, C.; Hu, C.; Ma, R.; Moore, T. Aquatic color radiometry remote sensing of coastal and inland waters: Challenges and recommendations for future satellite missions. Remote Sens. Environ. 2015, 160, 15-30. [CrossRef]

6. Qin, B.; Hu, W.; Gao, G.; Luo, L.; Zhang, J. Dynamics of sediment resuspension and the conceptual schema of nutrient release in the large shallow Lake Taihu, China. Chin. Sci. Bull. 2004, 49, 54-64. [CrossRef]

7. Tabata, M.; Ghaffar, A.; Nishimoto, J. Accumulation of metals in sediments of Ariake Bay, Japan. Electron. J. Environ. Agric. Food Chem. 2009, 8, 937-949.

8. Liu, H.; Wu, G.; Shi, T.; Hu, Z.; Zhou, Q. Estimating orthophosphate phosphorus concentration in Shenzhen Bay with remote sensing and legacy in-situ measurements. In Proceedings of the Earth Observation and Remote Sensing Applications, Guangzhou, China, 4-6 July 2016.

9. Cui, L.; Wu, G.; Liu, Y. Monitoring the impact of backflow and dredging on water clarity using MODIS images of Poyang Lake, China. Hydrol. Process. 2009, 23, 342-350. [CrossRef]

10. Herbeck, L.S.; Unger, D.; Krumme, U.; Liu, S.M.; Jennerjahn, T.C. Typhoon-induced precipitation impact on nutrient and suspended matter dynamics of a tropical estuary affected by human activities in Hainan, China. Estuar. Coast. Shelf Sci. 2011, 93, 375-388. [CrossRef]

11. Feng, L.; Hu, C.; Chen, X.; Tian, L.; Chen, L. Human induced turbidity changes in Poyang Lake between 2000 and 2010: Observations from MODIS. J. Geophys. Res. Oceans 2012, 117, C07006. [CrossRef]

12. Wu, G.; Cui, L.; He, J.; Duan, H.; Fei, T.; Liu, Y. Comparison of MODIS-based models for retrieving suspended particulate matter concentrations in Poyang Lake, China. Int. J. Appl. Earth Obs. Geoinf. 2013, 24, 63-72. [CrossRef]

13. Olmanson, L.G.; Brezonik, P.L.; Bauer, M.E. Evaluation of medium to low resolution satellite imagery for regional lake water quality assessments. Water Resour. Res. 2011, 47, 1900-1904. [CrossRef] 
14. Li, J.; Chen, X.; Tian, L.; Huang, J.; Feng, L. Improved capabilities of the Chinese high-resolution remote sensing satellite GF-1 for monitoring suspended particulate matter (SPM) in inland waters: Radiometric and spatial considerations. ISPRS J. Photogramm. Remote Sens. 2015, 106, 145-156. [CrossRef]

15. Gernez, P.; Lafon, V.; Lerouxel, A.; Curti, C.; Lubac, B.; Cerisier, S.; Barillé, L. Toward Sentinel-2 high resolution remote sensing of suspended particulate matter in very turbid waters: SPOT4 (Take5) Experiment in the Loire and Gironde Estuaries. Remote Sens. 2015, 7, 9507-9528. [CrossRef]

16. Dekker, A.; Vos, R.; Peters, S. Comparison of remote sensing data, model results and in situ data for total suspended matter (TSM) in the southern Frisian lakes. Sci. Total Environ. 2001, 268, 197-214. [CrossRef]

17. Pahlevan, N.; Schott, J.R. Leveraging EO-1 to evaluate capability of new generation of Landsat sensors for coastal/inland water studies. IEEE J. Sel. Top. Appl. Earth Obs. Remote Sens. 2013, 6, 360-374. [CrossRef]

18. Carpenter, D.; Carpenter, S. Modeling inland water quality using Landsat data. Remote Sens. Environ. 1983, 13, 345-352. [CrossRef]

19. Malenovský, Z.; Rott, H.; Cihlar, J.; Schaepman, M.E.; García-Santos, G.; Fernandes, R.; Berger, M. Sentinels for science: Potential of Sentinel-1, -2 , and -3 missions for scientific observations of ocean, cryosphere, and land. Remote Sens. Environ. 2012, 120, 91-101. [CrossRef]

20. Hansen, C.H.; Burian, S.J.; Dennison, P.E.; Williams, G.P. Spatiotemporal Variability of Lake Water Quality in the Context of Remote Sensing Models. Remote Sens. 2017, 9, 409. [CrossRef]

21. Manzo, C.; Bresciani, M.; Giardino, C.; Braga, F.; Bassani, C. Sensitivity analysis of a bio-optical model for Italian lakes focused on Landsat-8, Sentinel-2 and Sentinel-3. Eur. J. Remote Sens. 2015, 48, 17-32. [CrossRef]

22. Dörnhöfer, K.; Göritz, A.; Gege, P.; Pflug, B.; Oppelt, N. Water Constituents and Water Depth Retrieval from Sentinel-2A-A First Evaluation in an Oligotrophic Lake. Remote Sens. 2016, 8, 941. [CrossRef]

23. Kutser, T.; Paavel, B.; Verpoorter, C.; Ligi, M.; Soomets, T.; Toming, K.; Casal, G. Remote sensing of black lakes and using $810 \mathrm{~nm}$ reflectance peak for retrieving water quality parameters of optically complex waters. Remote Sens. 2016, 8, 497. [CrossRef]

24. Toming, K.; Kutser, T.; Laas, A.; Sepp, M.; Paavel, B.; Nõges, T. First Experiences in Mapping Lake Water Quality Parameters with Sentinel-2 MSI Imagery. Remote Sens. 2016, 8, 640. [CrossRef]

25. Vanhellemont, Q.; Ruddick, K. Landsat-8 as a precursor to Sentinel-2: Observations of human impacts in coastal waters. Procedings of the 2014 European Space Agency Sentinel-2 for Science Workshop, Frascati, Italy, 20-22 May 2014.

26. Palmer, S.C.; Kutser, T.; Hunter, P.D. Remote sensing of inland waters: Challenges, progress and future directions. Remote Sens.Environ. 2015, 157, 1-8. [CrossRef]

27. Salama, M.S.; Verhoef, W. Two-stream remote sensing model for water quality mapping: 2SeaColor. Remote Sens Environ. 2015, 157, 111-122. [CrossRef]

28. Vanhellemont, Q.; Ruddick, K. Advantages of high quality SWIR bands for ocean colour processing: Examples from Landsat-8. Remote Sens. Environ. 2015, 161, 89-106. [CrossRef]

29. Wang, Y.; Jia, Y.; Guan, L.; Lu, C.; Lei, G.; Wen, L.; Liu, G. Optimising hydrological conditions to sustain wintering waterbird populations in Poyang Lake National Natural Reserve: Implications for dam operations. Freshw. Biol. 2013, 58, 2366-2379. [CrossRef]

30. Zhao, X.; Barlow, J.; Taylor, B.L.; Pitman, R.L.; Wang, K.; Wei, Z.; Stewart, B.S.; Turvey, S.T.; Akamatsu, T.; Reeves, R.R. Abundance and conservation status of the Yangtze finless porpoise in the Yangtze River, China. Biol. Conserv. 2008, 141, 3006-3018. [CrossRef]

31. Yu, Z.; Chen, X.; Zhou, B.; Tian, L.; Yuan, X.; Feng, L. Assessment of total suspended sediment concentrations in Poyang Lake using HJ-1A/1B CCD imagery. Chin. J. Oceanol. Limnol. 2012, 30, 295-304. [CrossRef]

32. Wu, G.; De Leeuw, J.; Skidmore, A.K.; Prins, H.H.; Liu, Y. Comparison of MODIS and Landsat TM5 images for mapping tempo-spatial dynamics of Secchi disk depths in Poyang Lake National Nature Reserve, China. Int. J. Remote Sens. 2008, 29, 2183-2198. [CrossRef]

33. De Leeuw, J.; Shankman, D.; Wu, G.; de Boer, W.F.; Burnham, J.; He, Q.; Yesou, H.; Xiao, J. Strategic assessment of the magnitude and impacts of sand mining in Poyang Lake, China. Reg. Environ. Chang. 2010, 10, 95-102. [CrossRef]

34. Hou, X.; Feng, L.; Duan, H.; Chen, X.; Sun, D.; Shi, K. Fifteen-year monitoring of the turbidity dynamics in large lakes and reservoirs in the middle and lower basin of the Yangtze River, China. Remote Sens. Environ. 2017, 190, 107-121. [CrossRef] 
35. Wu, G.; Liu, L.; Chen, F.; Fei, T. Developing MODIS-based retrieval models of suspended particulate matter concentration in Dongting Lake, China. Int. J. Appl. Earth Observ. Geoinfor. 2014, 32, 46-53. [CrossRef]

36. Li, J.; Tian, L.; Chen, X.; Li, X.; Huang, J.; Lu, J.; Feng, L. Remote-sensing monitoring for spatio-temporal dynamics of sand dredging activities at Poyang Lake in China. Int. J. Remote Sens. 2014, 35, 6004-6022. [CrossRef]

37. Cui, L.; Qiu, Y.; Fei, T.; Liu, Y.; Wu, G. Using remotely sensed suspended sediment concentration variation to improve management of Poyang Lake, China. Lake Reserv. Manag. 2013, 29, 47-60. [CrossRef]

38. Mueller, J.L.; Morel, A.; Frouin, R.; Davis, C.; Arnone, R.; Carder, K.; Lee, Z.P.; Steward, R.G.; Hooker, S.; Mobley, C.D. Ocean Optics Protocols for Satellite Ocean Color Sensor Validation, Revision 4, Radiometric Measurements and Data Analysis Protocols; Tech. Memo 2003-21621; Goddard Space Flight Center: Greenbelt, MD, USA, 2003.

39. Ma, R.-H.; Tang, J.-W.; Dai, J.-F. Bio-optical model with optimal parameter suitable for Taihu Lake in water colour remote sensing. Int. J. Remote Sens. 2006, 27, 4305-4328. [CrossRef]

40. Drusch, M.; Del Bello, U.; Carlier, S.; Colin, O.; Fernandez, V.; Gascon, F.; Hoersch, B.; Isola, C.; Laberinti, P.; Martimort, P. Sentinel-2: ESA's optical high-resolution mission for GMES operational services. Remote Sens. Environ. 2012, 120, 25-36. [CrossRef]

41. Gordon, H.R.; Wang, M. Retrieval of water-leaving radiance and aerosol optical thickness over the oceans with SeaWiFS: A preliminary algorithm. Appl. Opt. 1994, 33, 443-452. [CrossRef] [PubMed]

42. Vermote, E.F.; Tanré, D.; Deuze, J.L.; Herman, M.; Morcette, J.-J. Second simulation of the satellite signal in the solar spectrum, 6S: An overview. IEEE Trans. Geosci. Remote Sens. 1997, 35, 675-686. [CrossRef]

43. Wang, M.; Shi, W. Cloud masking for ocean color data processing in the coastal regions. IEEE Trans. Geosci. Remote Sens. 2006, 44, 3196-3205. [CrossRef]

44. Vanhellemont, Q.; Ruddick, K. ACOLITE For Sentinel-2: Aquatic Applications of MSI Imagery. ESA Special Publication. Presented at the ESA Living Planet Symposium, Prague, Czech Republic, 9-13 May 2016.

45. Doxaran, D.; Froidefond, J.-M.; Lavender, S.; Castaing, P. Spectral signature of highly turbid waters: Application with SPOT data to quantify suspended particulate matter concentrations. Remote Sens. Environ. 2002, 81, 149-161. [CrossRef]

46. Petus, C.; Chust, G.; Gohin, F.; Doxaran, D.; Froidefond, J.-M.; Sagarminaga, Y. Estimating turbidity and total suspended matter in the Adour River plume (South Bay of Biscay) using MODIS 250-m imagery. Cont. Shelf Res. 2010, 30, 379-392. [CrossRef]

47. Wang, M.; Son, S.; Zhang, Y.; Shi, W. Remote Sensing of Water Optical Property for China's Inland Lake Taihu Using the SWIR Atmospheric Correction With 1640 and $2130 \mathrm{~nm}$ Bands. IEEE J. Sel. Top. Appl. Earth Observ. Remote Sens. 2013, 6, 2505-2516. [CrossRef]

48. Gordon, H.R.; Brown, O.B.; Jacobs, M.M. Computed relationships between the inherent and apparent optical properties of a flat homogeneous ocean. Appl. Opt. 1975, 14, 417-427. [CrossRef] [PubMed]

49. Wu, G.; Cui, L.; Duan, H.; Fei, T.; Liu, Y. Absorption and backscattering coefficients and their relations to water constituents of Poyang Lake, China. Appl. Opt. 2011, 50, 6358-6368. [CrossRef] [PubMed]

50. Lee, Z.; Carder, K.L.; Arnone, R.A. Deriving inherent optical properties from water color: A multiband quasi-analytical algorithm for optically deep waters. Appl. Opt. 2002, 41, 5755-5772. [CrossRef] [PubMed]

51. Kutser, T.; Vahtmäe, E.; Paavel, B.; Kauer, T. Removing glint effects from field radiometry data measured in optically complex coastal and inland waters. Remote Sens. Environ. 2013, 133, 85-89. [CrossRef]

52. Tian, L.; Wai, O.W.H.; Chen, X.; Li, W.; Li, J.; Li, W.; Zhang, H. Retrieval of total suspended matter concentration from Gaofen-1 Wide Field Imager (WFI) multispectral imagery with the assistance of Terra MODIS in turbid water-Case in Deep Bay. Int. J. Remote Sens. 2016, 37, 3400-3413. [CrossRef]

53. Novoa, S.; Doxaran, D.; Ody, A.; Vanhellemont, Q.; Lafon, V.; Lubac, B.; Gernez, P. Atmospheric Corrections and Multi-Conditional Algorithm for Multi-Sensor Remote Sensing of Suspended Particulate Matter in Low-to-High Turbidity Levels Coastal Waters. Remote Sens. 2017, 9, 61. [CrossRef]

54. Yang, X.; Zhao, S.; Qin, X.; Zhao, N.; Liang, L. Mapping of Urban Surface Water Bodies from Sentinel-2 MSI Imagery at $10 \mathrm{~m}$ Resolution via NDWI-Based Image Sharpening. Remote Sens. 2017, 9, 596. [CrossRef]

55. Deng, R.; Yingqing, H.E.; Qin, Y.; Chen, Q. Pure water absorption coefficient measurement after eliminating the impact of suspended substance in spectrum from $400 \mathrm{~nm}$ to $900 \mathrm{~nm}$. J. Remote Sens. 2012, 16, 174-191. 
56. Wu, G.; Cui, L.; Duan, H.; Fei, T.; Liu, Y. An approach for developing Landsat-5 TM-based retrieval models of suspended particulate matter concentration with the assistance of MODIS. ISPRS J. Photogramm. Remote Sens. 2013, 85, 84-92. [CrossRef]

57. Wang, M.; Shi, W.; Tang, J. Water property monitoring and assessment for China's inland Lake Taihu from MODIS-Aqua measurements. Remote Sens. Environ. 2011, 115, 841-854. [CrossRef]

58. Wang, M.; Son, S.; Shi, W. Evaluation of MODIS SWIR and NIR-SWIR atmospheric correction algorithms using SeaBASS data. Remote Sens. Environ. 2009, 113, 635-644. [CrossRef]

59. Franz, B.A.; Bailey, S.W.; Kuring, N.; Werdell, P.J. Ocean color measurements with the Operational Land Imager on Landsat-8: Implementation and evaluation in SeaDAS. J. Appl. Remote Sens. 2015, 9, 096070. [CrossRef]

60. Pahlevan, N.; Schott, J.R.; Franz, B.A.; Zibordi, G.; Markham, B.; Bailey, S.; Schaaf, C.B.; Ondrusek, M.; Greb, S.; Strait, C.M. Landsat 8 remote sensing reflectance (Rrs) products: Evaluations, intercomparisons, and enhancements. Remote Sens. Environ. 2017, 190, 289-301. [CrossRef]

(C) 2017 by the authors. Licensee MDPI, Basel, Switzerland. This article is an open access article distributed under the terms and conditions of the Creative Commons Attribution (CC BY) license (http://creativecommons.org/licenses/by/4.0/). 